\title{
Wyeomyia exallos, a new species of sylvatic mosquito (Diptera: Culicidae) from Brazil
}

\author{
Glauber Pereira Rocha, Ricardo Lourenço-de-Oliveira, Monique de Albuquerque Motta/+
}

Laboratório de Transmissores de Hematozoários, Instituto Oswaldo Cruz-Fiocruz, Rio de Janeiro, RJ, Brasil

Wyeomyia exallos, a new mosquito species from Atlantic Forest of southeastern Brazil, is described based on morphological characters of the adult female, male, male genitalia, pupa and fourth-instar larva. The morphological characters of Wy. exallos sp. nov. are compared with those of different subgenera of Wyeomyia as well as of species without subgeneric position. It is proposed that the new species should be placed in genus Wyeomyia Theobald without subgeneric assignment.

Key words: taxonomy - Serra da Mantiqueira - systematics - Sabethini - Wyeomyia

The new mosquito species validated and described herein was obtained during field collections performed at the Parque Nacional do Itatiaia (PARNA Itatiaia), state of Rio de Janeiro (RJ), Brazil, in 2002, when immature where taken from bromeliads and Aracea leaf axils, bamboos and tree holes, as well as adult captures. Only one adult female of the new species was caught when blood-feeding on one of the authors (MA Motta), in August 2002. It laid four eggs in the laboratory, one of which was unviable. Five year later, we conducted a one-year study on bromeliad mosquitoes in the same site at PARNA Itatiaia, in which immature and adult mosquitoes of several species were collected monthly, except Wyeomyia exallos sp. nov. Other eventual mosquito collections performed in the same site in recent years were negative for $W y$. exallos sp. nov. Therefore, we are describing this new species based on the few available specimens. We were encouraged to describe the new species because the genus Wyeomyia Theobald, the largest genus of tribe Sabethini among the Neotropical Culicidae, probably includes a small fraction of the true species diversity, as stressed by Belkin et al. (1970), Harbach and Peyton (1990) and Judd (1996).

\section{MATERIALS AND METHODS}

Morphological characters of the male, male genitalia, female, pupa and fourth-instar larva were examined. Pupal chaetotaxy was studied and the range and mode of branches are in Table. Because some setae of a few segments were lost from the available larval exuviae, chaetotaxy of the fourth-instar larva was not tabled. Illustrations are provided based on direct observation of morphological characters of the specimens and common setal position in Wyeomyia species. The descriptive terminology and abbreviations follow Belkin et al. (1970) and Harbach and Knight (1980). The specimens exam-

+ Corresponding author: mmotta@ioc.fiocruz.br Received 23 December 2011

Accepted 21 March 2012 ined are listed in the specific section. The holotype and the paratype are deposited in the Culicidae Collection (CCULI), Oswaldo Cruz Institute (IOC), RJ.

\section{Wy. exallos Rocha, Lourenço-de-Oliveira and Motta, sp. nov.}

(Figs 1-4)

Diagnosis - Wy. exallos sp. nov. may be easily distinguished by the combination of the following morphological characters: male genitalia with short gonocoxite bearing three moderately long tergal setae; gonostylus with a short stem, apically divided into three lobes; larva with maxilla bearing a short apical tooth, seta $4-\mathrm{Mx}$ single, pointed, seta 6-Mx single, abdomen with free scales on segment VIII (comb plate absent), forming one irregular row, siphon with a row of pectinate accessory setae (2a-S) and a pecten in two irregular rows, each comprised of about seven scales; pupa with seta 5-CT double, 1-II forked, 6-II as long as segment III, 7-II inserted dorsally, 6-VII inserted dorsally, 9-VII 0.5 length of 9-VIII; paddle shorter than length of segment VIII.

Female - Small mosquito. Head: vertex and occiput covered with dark scales with greenish-blue reflection, semi-erect scales absent, postgena with white scales; ocular line with dark brown scales, ocular setae dark brown, two long dark-brown interocular setae. Narrow interocular space, without setae and scales; clypeus ovate, brown, pruinose, without scales and setae; frons cream, pubescent, without setae and scales. Antenna: as long as proboscis, pedicel dark-brown, pruinose, with some bronzy scales and minute setae; flagellum slightly verticillate, whorls with about eight setae, flagellomere 1 with one tuff of scales. Maxillary palpus short, slightly longer than clypeus, brown-scaled, brown setae on apex. Proboscis brown, very expanded apically, length $2.0 \mathrm{~mm}$, approximately 0.85 length of forefemur; basal labial setae brown. Thorax: integument brownish. Antepronotum completely brown-scaled with greenishblue reflections, lobes well separated, a row of strong dark-brown setae dorsally. Postpronotum covered with white scales, upper postpronotal scales, dark. Scutum brown-scaled with greenish-blue reflections; scutal scales brownish with faint greenish-blue reflections. 
Anterior promontory area with few white scales and with approximately 10 dark-brown setae of different sizes. Scutellum with scales concolorous with those from scutum, about four, five long and six short dark-brown setae on each lobe. Mesopostnotum brown with a tuft of approximately six brown setae, without scales. Pleuron covered with whitish (cream-colored) scales, except on anterior lateral margin of mesokatespisternum, mesomeron and paratergite. Pleural setae: one yellowish prespiracular setae; postspiracular setae absent; five long yellowish (with dark insertion) upper proepisternal setae; five bronzy lower mesokatepisternal setae above anterior margin of mesomeron; upper mesokatepisternal setae absent; five brown prealar setae; lower mesepimeral setae absent; 11 yellowish upper mesepimeral setae. Legs: fore, mid and hindcoxae with white scales on anterior surface and bronzy setae over all. Forefemur longer than proboscis, ventrally with a longitudinal stripe of white scales, foretibia and foretarsomeres dark-scaled. Midlegs broken (lost); hindfemur with a longitudinal stripe of white scales ventrally; hindtibiae same length as hindfemur, dark-scaled, hindtarsomeres dark-scaled. Ungues simple. Wing: length $2.7 \mathrm{~mm}$. Upper calypter with two dark-brown setae. Alula with nine simple, dark-brown setae. Wing with brown scales. Dorsal scales: $\mathrm{R}_{1}, \mathrm{R}_{2+3}, \mathrm{R}_{2}, \mathrm{R}_{\mathrm{s}}, \mathrm{R}_{3}, \mathrm{R}_{4+5}, \mathrm{M}_{1}$ and $\mathrm{M}_{2}$ with lateral setae elongate, slightly broad; proximal part of vein $M$ with anterior scales narrow, ligulate, decumbent scales not exceeding the vein width; $\mathrm{CuA}$ with narrow decumbent scales, not exceeding the vein width. Halter: integument yellowish, scabellum and pedicel darkscaled dorsally, capitellum dark-scaled. Abdomen: terga covered with brown scales; without lateral incisions of white scales, tergum I with a row of yellowish setae on posterolateral margin; some short bronzy setae on apex of tergum VIII; sterna with white scales similar in colour to pleural scales.

Male - Similar to female, except for antenna slightly more verticillate, proboscis length $1.5 \mathrm{~mm}$. Wing length $2.4 \mathrm{~mm}$. Legs: midfemur, midtibia and midtarsomeres I, II dark-scaled; midtarsomeres III-V darkish, with a line of whitish scales ventrally; hindtarsomere $\mathrm{V}$ with some whitish scales on one side.

Male genitalia (Fig. 1) - Tergum and sternum VIII not examined (not possible). Tergum IX (Fig. 1E) narrow, interlobar space slightly concave, lobes not pronounced, each bearing four, five long setae with fine apex. Proctiger (Fig. 1D) membranous, tergum $X$ weakly pigmented; paraproct sclerotized with one main tooth and one adjacent, nearly indistinct, narrow tooth above; three short cercal setae. Aedeagus (Fig. 1C) with rounded apical tergal arms fused, forming a slightly concave apex; median sternal plate membranous, apically folded outward; submedian tergal arms fused. Gonocoxite (Fig. 1A): short, larger on base; tergal surface with minute setae and three moderately long setae. Sternal surface with minute setae and scales, a tubercle on anterior surface; basal mesal lobe slightly rectangular covered with minute setae, about four-six moderately long setae and one long seta on inner angle. Gonostylus (Fig. 1A, B) shorter than gonocoxite, approximately 0.5 length of gonocoxite, formed by a stem apically divided into three lobes: lobe A digitiform, apically with two stout setae, lobe E rounded with numerous short setae along the anterior surface; lobe $\mathrm{C}$ slender, slightly curved with pointed apex.

TABLE

Range of branches for pupal setae in Wyeomyia exallos sp. nov. (mode in parentheses) $(\mathrm{n}=2)$

\begin{tabular}{|c|c|c|c|c|c|c|c|c|c|}
\hline \multirow[b]{2}{*}{ Setae } & \multirow[b]{2}{*}{ Cephalothorax } & \multicolumn{8}{|c|}{ Abdominal segments } \\
\hline & & I & II & III & IV & V & VI & VII & VIII \\
\hline 0 & - & - & 1 & 1 & 1 & 1 & 1 & 1 & 1 \\
\hline 1 & 2 & $\mathrm{D}$ & 6,7 & 1,2 & 1 & 1,2 & $1,2(1)$ & 1 & - \\
\hline 2 & 2 & 1,2 & 1 & 1 & 1 & 1 & 1 & 1 & - \\
\hline 3 & $2,3(3)$ & 1 & 1 & $1,2(1)$ & 1,3 & 1,2 & $1,2(1)$ & 1 & - \\
\hline 4 & 3 & $1-3$ & 2 & $1,2(1)$ & $1,2(2)$ & $1,2(2)$ & $1,2(1)$ & 1 & 1 \\
\hline 5 & 2 & 1,2 & 1,2 & 2 & 1 & 1 & 1 & 1 & - \\
\hline 6 & 2 & 1 & 1 & $1,2(2)$ & $1,2(1)$ & 1 & 1 & 1 & - \\
\hline 7 & 2 & 2 & 1 & 2 & $1,2(1)$ & $1-3(2)$ & 1 & 1 & - \\
\hline 8 & 1 & - & - & 1,3 & $1-3(2)$ & $2,4(3)$ & 3 & $2,3(2)$ & - \\
\hline 9 & 1,2 (1) & 1 & 1 & $1-3(1)$ & 1 & 1 & 1 & $\begin{array}{l}14,16 \\
18,21\end{array}$ & $\begin{array}{l}14,16 \\
20,22\end{array}$ \\
\hline 10 & 1,2 (1) & - & 1 & $1,2(2)$ & 1,2 (1) & $1,2(1)$ & 1 & 1 & - \\
\hline 11 & 1 & - & 1 & 1 & $1,2(1)$ & $1,2(1)$ & 1 & 1,2 (1) & - \\
\hline 12 & $1,2(2)$ & - & - & - & - & - & - & - & - \\
\hline 14 & - & - & - & - & - & - & - & - & 1 \\
\hline
\end{tabular}

D: dendritic. 
Pupa (Fig. 2) - Character and positions of setae as figured; range and modal number of branches in Table. Cephalothorax (Fig. 2A): integument very pale, seta 1-CT sigmoidal with slightly hooked apex; seta 2-CT double, short; 3-CT double, long; 4-CT usually triple; 5-CT developed, slightly aciculate; $8,9-\mathrm{CT}$ similar in development. Trumpet narrow, elongate, index 7.0-8.7 (measured at middle length). Abdomen (Fig. 2B): very pale, median anterior margin of ventral surface II-VII darker, punctures (not shown in Fig.) on lateral anterior third on segment II-VII. Seta zero minute, single; seta 1-I dendritic with three main branches; 1-II forked usually with six, seven branches, 1-IV-VI single or double, usually single on VI, single on VII, 1-III lateral to 3-III; 2-II-VII short, single, mesal to seta 1; 3-I-III often single, as long as next tergum, much shorter on segments IV-VII; seta 4-II, IV, V more often double, 4-III, VI-VIII usually single; 5-III, VII similar in development, 5-IV-VI stronger, slightly longer than following tergum, 5-V, VI slightly aciculate; seta 6-II as long as tergum III, 6-III double, 6-III-V posteromesal to 9-III-V, 6-V-VII usually single, seta 7-I, III (and usually 7-V) normally double, 7-II single, dorsal, 7-IV usually single, 7-VI single; 8-IV-VII usually double, 8-V (and usually 8 -VI) triple; seta 9-I-VI short and single, 9-VII, VIII with multiples aciculate branches, 9-VIII twice as long as paddle; setae 10, 11-I not found, seta 10-II-VII normally single, 10-III-V sometimes double; 11-II, III usually single, 11-IV, V, VII sometimes double. Paddle: shorter than segment VIII, index: 1.5, 1.6 (width measured at middle length), gradually tapered toward apex, spiculate apically. Midrib well marked. Male genital lobe darker than abdominal segments, elongate with rounded apex.

Fourth-instar larva (Figs 3, 4) - Character and positions of setae as figured. Head: lightly pigmented, wider than long. Slits of occipital foramen extended laterally, margins not pigmented, except in ocular area; hypostomal suture complete. Dorsomentum with 10, 11 teeth on each side of a large central prominent tooth. Maxilla (Fig. 4B, E): apical tooth small, slightly curved; maxillary brush formed by numerous, long setae, slightly longer than seta 4-Mx; laciniarastrum: LR1 composed by approximately nine teeth progressively longer toward apex; LR2 with numerous long setae; seta 1-Mx, short, peg-like, bifid, inserted apicolaterally; seta $2-4-\mathrm{Mx}$ single; 3-Mx without notch (sensu Judd 1996); seta 4-Mx single, pointed; 6-Mx single, hair-like, inserted on cardo; maxillary palpus not fused to maxilla, with three apical setae. Mandible (Fig. 4A, D): short, somewhat rectangular in lateral view, dorsal tooth stout, ventral teeth stronger. Seta 2 single, strong; mandibular spiculose area with few spicules; mandibular rake comprised of about three pectunculate setae; mandibular sweeper 1 comprised of eight setae, mandibular sweeper 2 formed of five setae. Antenna slender, seta 1-A single, flexible, inserted on apical third of antenna. Seta 1-C stout, slightly curved, in lateral view; seta 4-8-C single, 9-C double or triple,
A

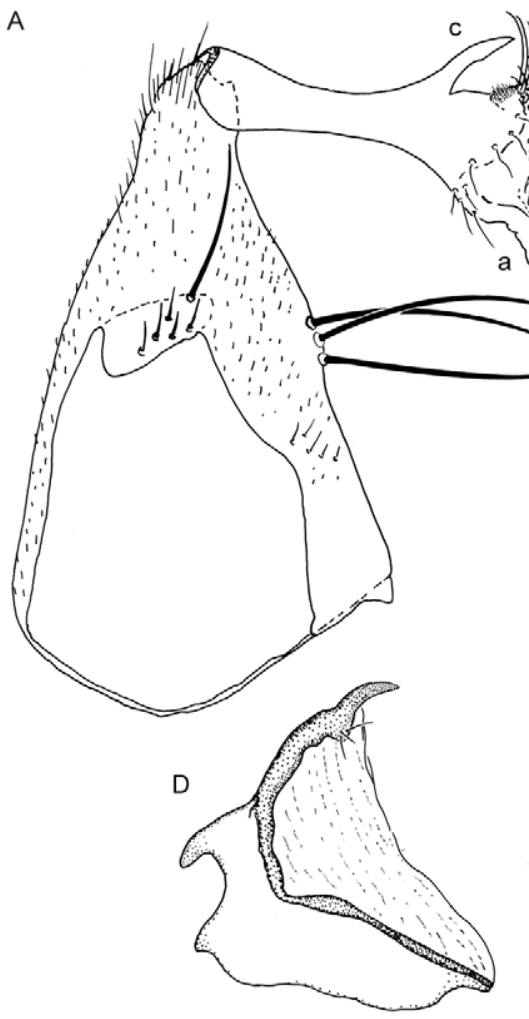

B

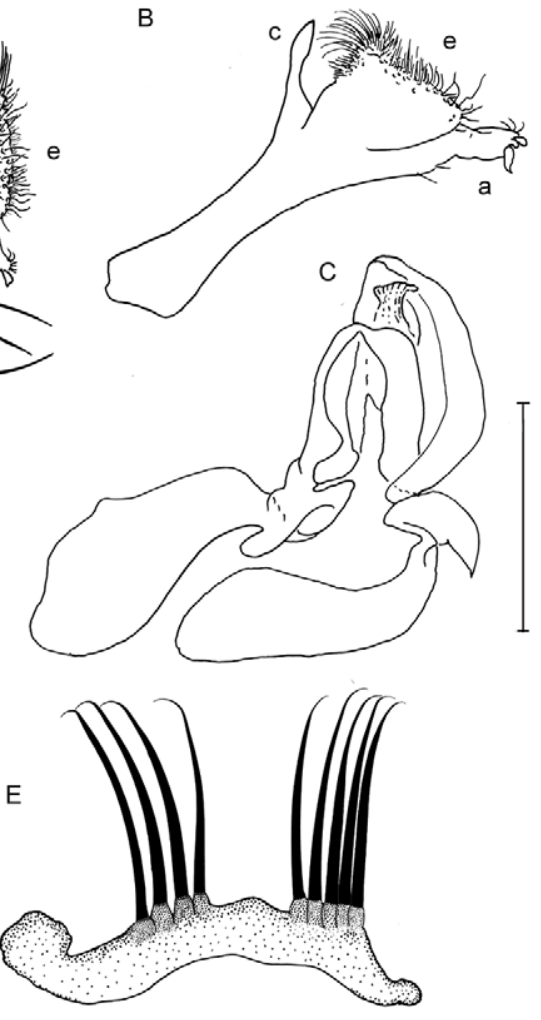

Fig. 1: male genitalia of Wyeomyia exallos sp. nov. A: gonocoxite and gonostylus, mesal view (lobes a, c, e,); B: gonostylus, lateral view; C: phallosome; D: proctiger; E: tergum IX. Bar $=0.5 \mathrm{~mm}$. 
A

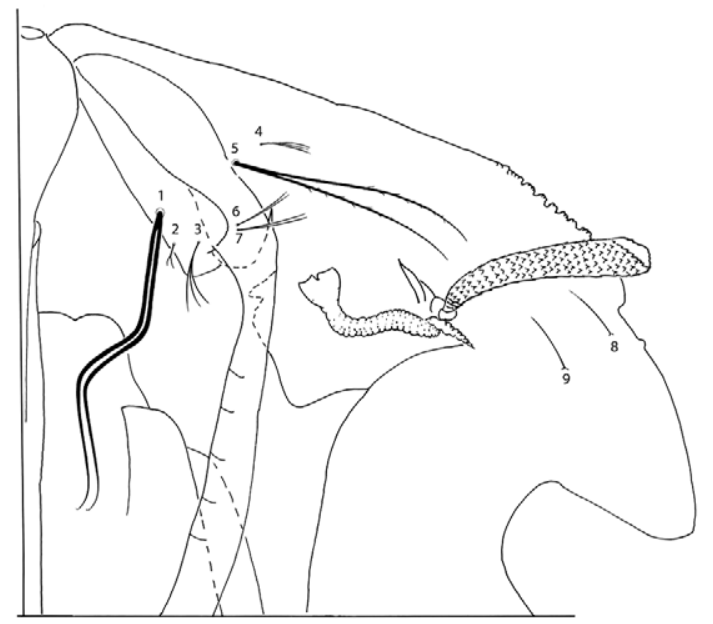

B

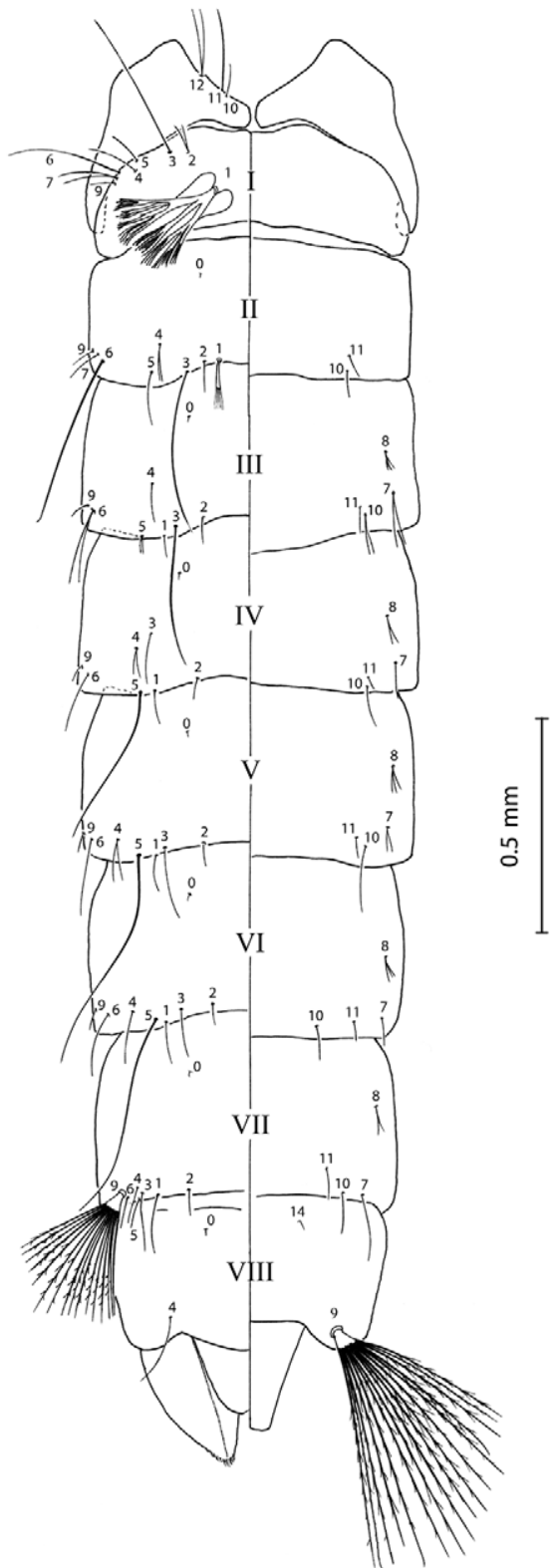

Fig. 2: pupa of Wyeomyia exallos sp. nov. A: cephalothorax; B: dorsal and ventral aspects of metanotum and abdomen.
10-C single, 11-C with six branches, 12-C 4-branched, 13-C double, similar in length to $12-\mathrm{C}, 14-\mathrm{C}$ not strongly developed, double; 15-C arising at middle of labiogula, small. Thorax: integument smooth, seta 0-P with six branches, similar in development to seta 1, seta 1-P, M, T similarly developed, multibranched, with four, five and three branches, respectively; 2-P, double; 2-M, T single; 3-P, M single, 3-T double; 4-P with seven branches, successively arising on one side of main stem, 4-M short, double, 4-T single; 5-P, M well developed, single aciculate, 5-T short with six branches; 6-P, M single aciculate, 6-T small double; 7-P well developed, 5-branched, 7-M short, double, 7-T smaller than 13-T, with six branches; 8-P short, 5-branched, 8-M well developed, triple, aciculate, 8-T minute, triple; 9-P double aciculate, 9-M single, aciculate, 9-T well developed, triple, aciculate; 10-P, M, T single, shorter than seta 9-P, M, T; 11-P, M, T hair-like, single or double; 12-P double, aciculate, 12-M, T single, aciculate; 13-M 5-branched, short, similar in development to 14-M, 13-T with nine aciculate branches; 14-M 6-branched. Abdomen: integument smooth. Dorsal and ventral setae of segment I, II and ventral setae of segment III not described nor illustrated except for setae 6-I, II and 7-I, II. Seta 1-III-VII similar in development, seta 1-III, IV double, 1-V, VII, 4-branched, 1-VII slightly aciculate, seta 1-VI triple, 1-VIII shorter than 1-III-VII 8-branched; 2-III-VII single, small, 2-VIII longer than 2-III-VII, single; 3-III double, slightly shorter than 5-III, 3-IV, VI triple, 3-V, VIII long, single; 3-VII well developed, double aciculate; seta 4-III, IV short, single, 4-V, VI triple, 4-VI longer than 4-V, 4-VII single, moderately long; seta 5-III, IV triple, 5-IV, V longer than 5-III, VI, 5-VII minute, triple, 5-VIII well developed, double; seta 6-I, II with 6.5 long aciculate branches, seta 6-III, VI double, aciculate, 6-IV with four aciculate branches, 6-V triple, aciculate, 6-VII short, with four branches; 7-I, II with six aciculate branches; 7-IV, VI short, double, 7-V with five branches, 7-VII single; 8-III not found, seta 8-IV, V minute, 8-IV triple, 8-V double, 8-VI not found, 8-VII with six branches; 9-IV-VI very short, 9-IV single, 9-V, VI double, 9-VII 5-branched; 10-IV double, $10-\mathrm{V}$ triple, 10-VI, VII longer, single; 11-IV-VII very short, 11-IV single, 11-V triple, 11-VI, VII double; 12IV, V single, 12-VI, VII double; 13-IV, V, VII well developed, multibranched, 13-VII slightly aciculate, 13-VI 7-branched, shorter than seta 13 on other segments. Segment VIII: 1-VIII with eight branches 2, 3-VIII single, seta 4-VIII with five branches, 5-VIII well developed, long, double, aciculate, comb plate absent, comb with 11 scales arranged in one irregular row, scales of similar size. Siphon: tanned, basal edge pigmented, elongate, index 2.9, 3.6, widest at base, smooth surface, pecten in two irregular rows comprised of about seven elongate scales, fringed on apex; seta 1-S arising close to siphon base, five pairs of anterolateral accessory seta (2a-S), pectinate, two-four branches, arranged in one row, most basal seta inserted in line with seta 1-S. Segment X: saddle complete, integument lightly pigmented, smooth, without spicules on posterior margin, seta 1, 3-X double, aciculate; seta $2-X$ single; seta $4-X$ long, aciculate, inserted on saddle margin. 
Type data and depository - Holotype: adult male (1 foreleg and 1 wing missing) with associated larval and pupal exuviae and dissected male genitalia on microscope slide 2401, PARNA Itatiaia $\left(22^{\circ} 25^{\prime} 43.04^{\prime \prime} \mathrm{S}\right.$ 443'ㄷ․ $\left.56^{\prime \prime} \mathrm{W}\right)$, M Motta coll., August 2002, M Motta det.2008, sibling of a female collected when blood-feeding on human. Paratype: female (2 midlegs missing), Le and Pe on microscope slide 2402, same data as holotype. The specimens are deposited in the Laboratório de Transmissores de Hematozoários, CCULI, IOC.

Distribution - Wy. exallos sp. nov. is known only from the type locality, PARNA Itatiaia. The environment is Atlantic Rain Forest, with abundant bromeliads, bamboos and Araucaria; it is approximately $1,081 \mathrm{~m}$ altitude.
Bionomics - Examined specimens are the progeny of a single wild-caught female on human attraction that laid four eggs in the laboratory and died. Despite several searches, the immature stages of Wy. exallos sp. nov. were not found during numerous samplings from bromeliads, bamboos and other phytotelmata conducted during about two years at PARNA Itatiaia.

Etymology - The Greek adjective exallos is both masculine and feminine, meaning quite distinct.

Taxonomic discussion - Wy. exallos is very distinct in practically all life stages from the other described Wyeomyia species. In general view, the adult female of $W y$. exallos is a typical mosquito belonging to genus Wyeomyia in presenting the greenish-blue opaque coloration,

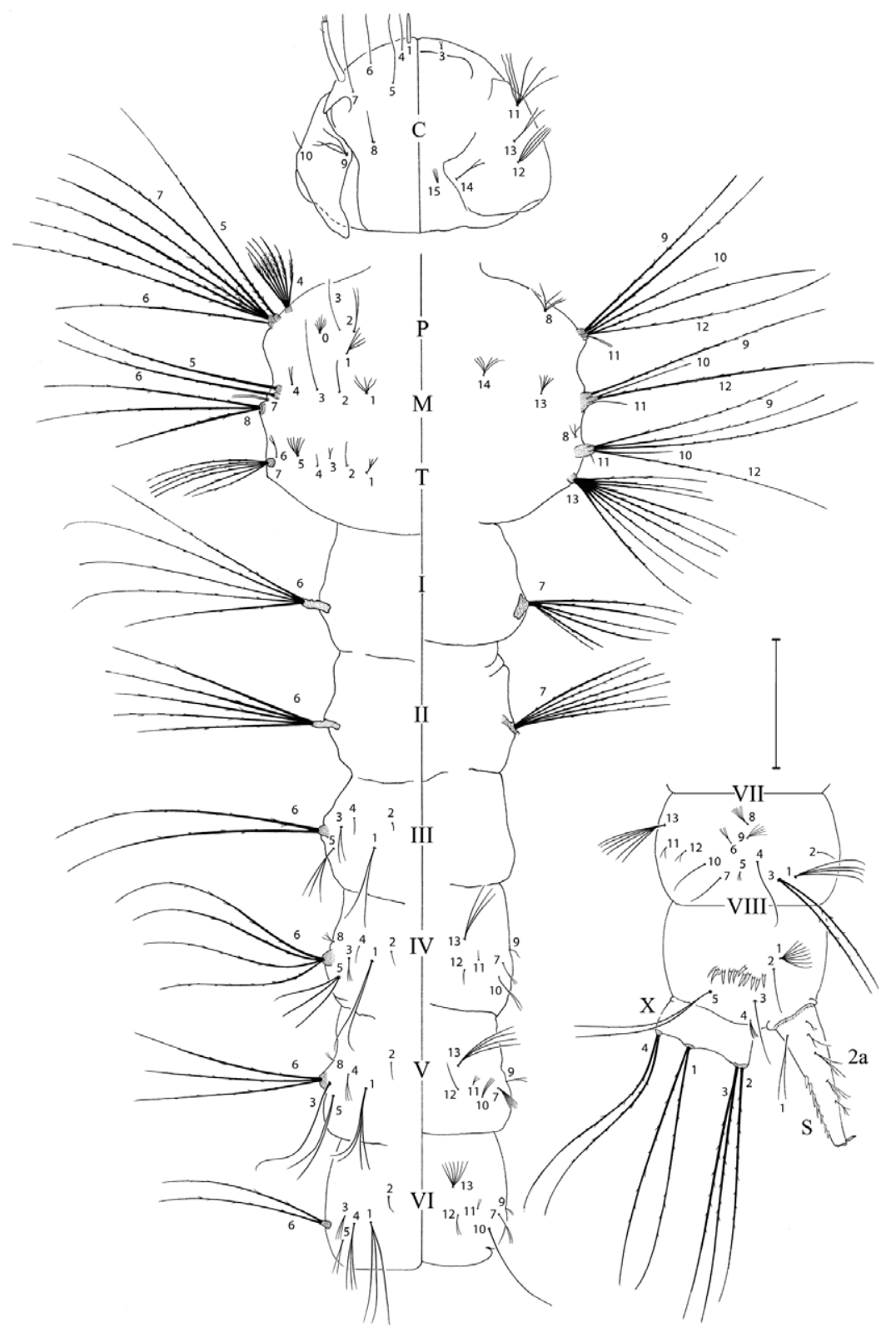

Fig. 3: fourth-instar larva of Wyeomyia exallos sp. nov. Dorsal and ventral aspects of the head, thorax and abdominal segments I-VI, lateral aspect of abdominal segments VII, VIII and X. C: cranium; M: mesothorax; P: protorax; S: siphon; T: metathorax. Bar $=0.5 \mathrm{~mm}$. 
on the antepronotum and scutum. Thus, its distinction based on the overall feature of the female is not possible. However, the other species of genus Wyeomyia that share this feature are very distinct from Wy. exallos in the other life stages and male genitalia. We compared the female morphological characters of $W y$. exallos with those of three Wyeomyia species that have been described only from females. We contrasted the female morphology of Wy. exallos with the lectotype female of Wyeomyia rooti (Del Ponte), as well as with the description of Wyeomyia moerbista (Dyar \& Knab) and Wyeomyia cesari Del Ponte \& Cerqueira. Female of $W y$. exallos differs from $W y$. rooti in the absence of white scales forming a spot in the occiput and vertex and white scales on the ocular line. Wy. exallos is distinct from Wy. moerbista and $W y$. cesari in the absence of white scales on dorsal and ventral area of the antepronotum.

Several Wyeomyia species have been described based only on morphological characters of one gender whereas several other species have not been associated with immature stages. This has made it difficult to determine the taxonomic status of several species as well as to clearly establish the phylogenetic relationships within the genus Wyeomyia. In an attempt to assign Wy. exallos to a subgenus in the genus Wyeomyia, we compared its morphological features with those of well characterized Wyeomyia subgenera and the Wyeomyia species of uncertain placement (Motta \& Lourenço-de-Oliveira 1995). However, $W y$.
A

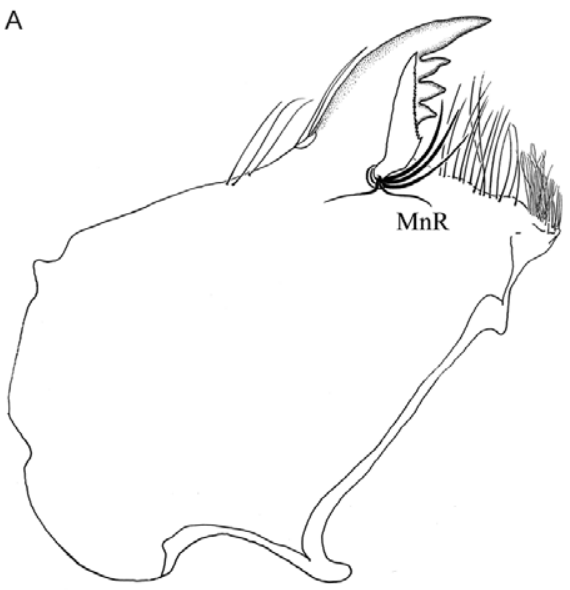

C

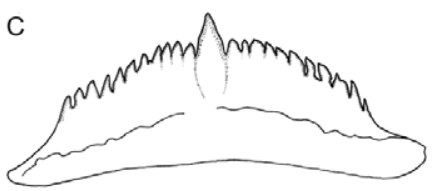

D

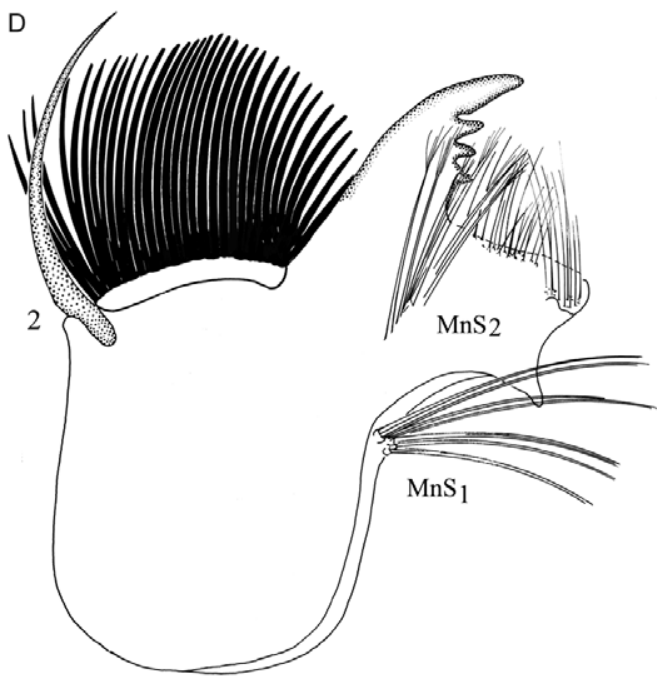

B
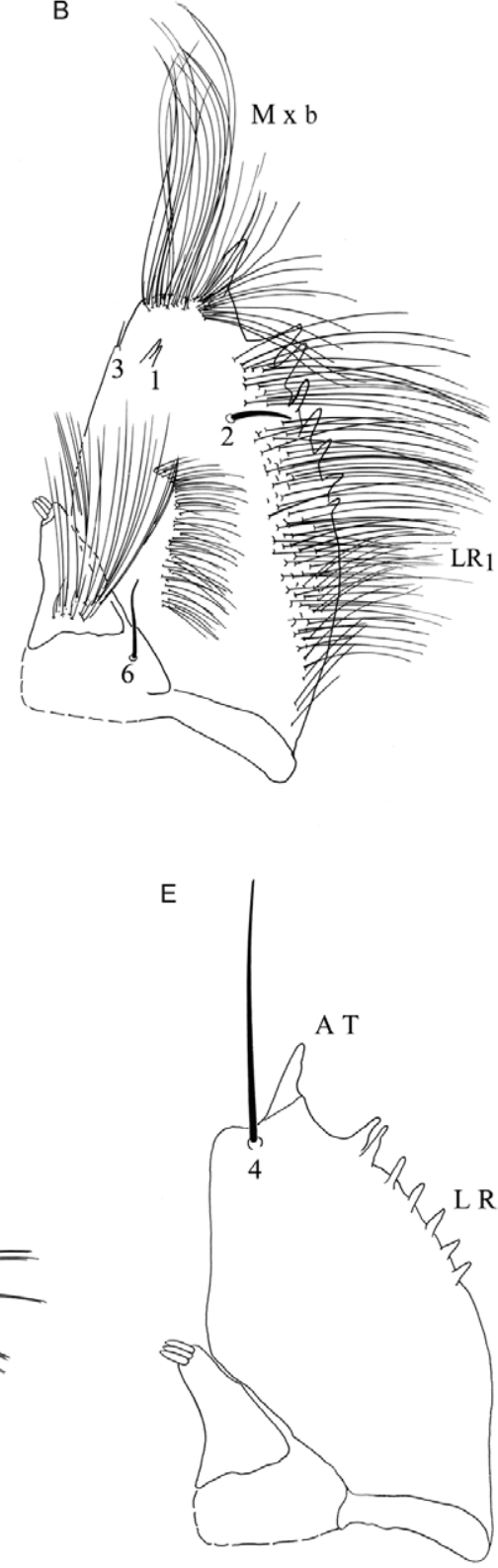

Fig. 4: larval mouthparts of Wyeomyia exallos sp. nov. A, D: mandible; AT: apical tooth; B, E: maxillae (A, E: ventral views; B, D: dorsal views); C: dorsomentum; LR: laciniarastrum; MnR: mandibular rake; MnS: mandibular sweeper; M x b: maxillary brush. Bar $=0.5 \mathrm{~mm}$. 
exallos did not fit into any known group and the natural affinities of the new species could not be determined. In fact, morphological features of $W y$. exallos are quite different from species of the recognized Wyeomyia subgenera. In the subgenera Dendromyia Theobald, Prosopolepis Lutz and Caenomyiella Harbach \& Peyton, the male genitalia have the gonostylus basally divided, without a stem; the fourth-instar larva possesses developed maxillary apical tooth and a short seta 4-X. The subgenera Zinzala Zavortink, Miamyia Dyar and Antunesmyia Lane \& Cerqueira possess male genitalia with numerous setae on the proctiger or the gonostylus is not divided into three lobes and with the fourth-instar larva have conspicuous stellate setae on the abdominal segments. In the subgenera Hystatomyia Dyar, Phoniomyia Theobald and Dodecamyia, the gonostylus has no apical lobes and the fourth-instar larvae have a siphon with numerous accessory setae and comb scales in more than one row. Species of subgenus Triamyia Dyar possesses a gonostylus with different features and larvae without pecten. In the poorly known subgenus Nunezia Dyar, the larva of the only species whose immature stages is described has more than one row of comb scales and the gonostylus does not possess the lobe C. Subgenera Spilonympha Motta \& Lourenço-de-Oliveira and Cruzmyia Lane \& Cerqueira include species in which the gonostylus has very distinct lobes apically, larva possess numerous accessory setae on the siphon and a comb plate on segment VIII. Species of Decamyia Dyar have the basal plate of the male genitalia with a long seta and larvae with more than two rows of comb scales. Wy. exallos differs from species of the subgenus Exallomyia by having the gonostylus with a tuft of long setae, the larva with a row of long seta 1a-S and a well-developed seta 1-A inserted on the 0.5 basal of the antenna. The subgenus Wyeomyia Theobald is a very heterogeneous group of numerous species and is considered to be polyphyletic (Judd 1996, Motta et al. 2007). Therefore determining affinities with $W y$. exallos is problematic at present.

Wy. exallos is morphologically similar to Wyeomyia melanocephala Dyar \& Knab, a species of uncertain subgenus (Motta \& Lourenço-de-Oliveira 1995), in having the gonostylus apically divided into three lobes. In the larval stage, Wy. exallos also shares some characters with $W y$. melanocephala, such as seta $4-\mathrm{X}$ usually double, long and inserted at the margin of the saddle and the siphon with a row of pectinate accessory setae, which is also characteristic of Wyeomyia (Menolepis) leucostigma (Lutz). Nonetheless, none of these morphological comparisons have not allowed establishing the subgeneric position of $W y$. exallos, neither elucidated its taxonomic position into the genus Wyeomyia. Currently the genus Wyeomyia comprises 17 subgenera (Harbach 2012), however, not all subgenera are well characterized in all life stages and much needs to be done to clarify in the taxonomy of Wyeomyia. We consider that it would be premature at this time to propose a new subgenus for $W y$. exallos, which would not help to realize a natural classification for the genus Wyeomyia. Thus, we propose Wy. exallos be placed in genus Wyeomyia, without subgeneric assignment.

\section{ACKNOWLEDGEMENTS}

To Heloisa Diniz, from the Laboratory of Image Treatment, IOC, for assistance in preparing figures, to Léo Nascimento, from PARNA Itatiaia, for support in the field and permission to make the collections, and to the two reviewers, for their great contribution to the improvement of the text.

\section{REFERENCES}

Belkin JN, Heinemann SJ, Page WA 1970. Mosquito studies (Diptera: Culicidae) XXI. The Culicidae of Jamaica. Contrib Amer Entomol Inst 6: 1-458.

Harbach RE 2012. [homepage on the Internet] [updated 2012 Feb 15; cited 2012 Feb 17]. Mosquito taxonomic inventory. Available from: mosquito-taxonomic-inventory.info/genus-wyeomyia-theobald1901.

Harbach RE, Knight KL 1980. Taxonomists' glossary of mosquito anatomy, Plexus Publ, Marlton, 415 pp.

Harbach RE, Peyton EL 1990. A new subgenus in Wyeomyia (Diptera: Culicidae) with the reclassification and redescription of the type species, Sabethes fernandezyepezi. Mosq Syst 22: 15-23.

Judd DD 1996. Review of the systematics and phylogenetic relationships of the Sabethini (Diptera: Culicidae). Syst Entomol 21: 129-150.

Motta MA, Lourenço-de-Oliveira R 1995. Wyeomyia luteoventralis Theobald, the type species of the subgenus Dendromyia Theobald (Diptera: Culicidae). Mem Inst Oswaldo Cruz 90: 375-385.

Motta MA, Lourenço-de-Oliveira R, Sallum MAM 2007. Phylogeny of genus Wyeomyia (Diptera: Culicidae) inferred from morphological and allozyme data. Can Entomol 139: 1-37. 